\title{
Borsa İstanbul'da İşlem Gören İmalat Sanayi Şirketlerinin Sermaye Yapılarının Firmaya Özgü Belirleyicileri
}

Nida ABDIOG $\breve{G} \boldsymbol{U}$, Department of Business Administration, Faculty of Economics and Administrative Sciences, Bandirma Onyedi Eylul University, Turkey; e-mail: nidaabdioglu@balikesir.edu.tr

Devran DENIZ, Department of Business Administration, Faculty of Economics and Administrative Sciences, Bandirma Onyedi Eylul University, Turkey; e-mail: devrandnz@gmail.com

\section{The Determinants of Capital Structure for the Manufacturing Industry Firms Listed in Borsa Istanbul}

\begin{abstract}
This paper investigates the factors that determine the capital structure of the manufacturing industry firms that are listed in BIST between the period 2009 and 2013. We use the data for 188 firms that are included in sub sectors of manufacuring industry. These sectors are food-beverage-tobacco, textile-wearing apparel-leather, paper and paper products-printing-publishing, chemicals-petroleum rubber-plastic products, nonmetalic mineral products, basic metal industries, fabricated metal products-machinery-equipment, wood products including furniture. We use the ratio of total debt to total liabilities as a proxy for capital structure. We also use random effect panel regression to run our analyses. Our findings indicate consistent results with pecking order theory.
\end{abstract}

Keywords

Capital Structure, Pecking Order Theory, Static Trade-off Theory, Panel Data Analysis.

JEL Classification Codes : $\quad$ G30, G32.

\section{$\ddot{\mathbf{O} z}$}

Bu çalışmada, BİST’te işlem gören imalat sanayi sektöründe faaliyet gösteren şirketlerde sermaye yapısını belirleyen faktörler 2008 finansal krizi sonrası 5 yıllık dönem verileriyle araştırılmıştır. Araştırma, imalat sanayinin; gıda- içki- tütün, dokuma- giyim eşyası- deri, kâğıt ürünleri-basım-yayın, kimya-petrol- kauçuk- plastik ürünler, taş ve toprağa dayalı sanayi, metal ana sanayi, metal eşya- makine- gereç yapım ve orman ürünleri- mobilya alt sektörlerinden 188 şirket ile yapılmıştır. Bağımlı değişken olarak şirketlerin sermaye yapısını temsilen toplam borç/toplam pasif oranı kullanılmıştır. Çalışmada rassal etkiler panel veri analizi kullanılmış ve bulgular çeşitli sermaye yapısı teorileri ile ilişkilendirilmiştir. Sonuçta, değişkenler arasında genellikle finansman hiyerarşisini destekleyen ilişkiler bulunmuştur.

Anahtar Sözcükler $\quad$ : Sermaye Yapısı, Finansman Hiyerarşisi, Dengeleme Teoremi, Panel Data Analizi. 


\section{Giriş}

Sermaye yapısı, finans yazınının 1950'lerden bu güne en fazla tartışılan konularından biri olmuştur. Sermaye yapısından kastedilen şirketlerin yükümlülüklerindeki borç/öz sermaye dengesidir (Başaran, 2008: 137). Sermaye yapısı, kısa vadeli borçları hariç tutmak suretiyle uzun vadeli borç ve öz sermaye dengesini anlatmak için de kullanılmaktadır (Başaran, 2008: 4). Tartışma sermaye yapısının sermaye maliyetini dolayısıyla firma değerinin etkileyip etkilemediği ve sermaye yapısının belirleyicilerinin neler olduğu etrafında yoğunlaşmıştır (Sheikh \& Wang, 2011: 118). Bu çalışmada, BİST'te işlem gören imalat sanayi sektöründeki işletmelerin sermaye yapısının firmaya özgü belirleyicilerinin 2008 finansal kriz sonrası verilerle görülmesi amaçlanmıştır.

2008 finansal krizi sonrasında başta ABD olmak üzere gelişmiş ülke merkez bankalarının uygulamış oldukları genişlemeci para politikaları gelişmekte olan ülkelere yönelik yabancı sermaye akışını artırmıştır. Hatta bizatihi gelişmekte olan ülke merkez bankalarının uyguladıkları genişlemeci para politikaları da piyasada likiditeyi artırmıştır (Barlas \& Kaya, 2013: 2) ${ }^{1}$. Bu durumun firmaların borç maliyetlerini düşürdügü ve sermaye yapılarında borç artış1 yönünde değişikliğe sebep olduğu düşünülmektedir. Ancak uygulama sonunda imalat sanayi sektöründeki işletmelerin sermaye yapısında borcun payının düştüğü tespit edilmiştir. Sermaye yapısını açıklayan firmaya özgü bağımsız değişkenlerle sermaye yapısı arasındaki ilişkilerin ise önceki yıllarda yapılan çalışmalardakine benzerlik gösterdiği görülmüştür.

Bu çalışmada imalat sanayi sektöründeki 8 endüstrinin sermaye yapılarının aynı dönem verileri ile incelenmesi hedeflenmektedir. Çalışmada imalat sanayi sektörünün seçilmesindeki sebep, Türkiye Cumhuriyeti hükümeti tarafından ilan edilen 2015-2017 orta vadeli mali programda üretim ve büyümede imalat sanayi payının artırılmasına yönelik hedef belirtilmesi ve bu hedef doğrultusunda çeşitli eylem planlarının yer alması olmuştur (R.G. No: 29142, 11.10.2014, 2014/28 Sayılı Karar). Büyüme hızı ve sektördeki şirketlerin büyüklüğünün artması ile sermaye yapısı arasındaki tespit edilecek ilişki anılan dönemde sektörün sermaye yapısının ne yönde değişebileceği hakkında fikir verecektir. Bunun dışında imalat sanayi sektörünün toplam GSYH ve toplam ihracat içindeki payının sırasıyla $\% 19,5^{2}$ ve \%93,5 gibi oldukça yüksek seviyede olması bu sektörün incelenmesinde etkili

1 2008-2013 döneminde FED bilançosu 800 milyar USD'den yaklaşık 3 trilyon USD seviyesine kadar yükselmiştir (Barlas \& Kaya, 2013: 2).

2 TOBB, Ekonomik Rapor, 2008: s 42.

3 TÜ̈K, <http://www.tuik.gov.tr/PreHaberBultenleri.do?id=16076>, 10.01.2014. 
olmuştur. Zira ülkemiz ekonomisi açısından hem GSYH hem de ihracat içinde imalat sanayi sektörü oldukça önemli yer tutmaktadır.

Çalışmanın sonucunda, firmaya özgü değişkenlerin sermaye yapısındaki değişimin \%36'lık kısmını açıkladığı ve değişkenler arasındaki ilişkilerin genellikle finansman hiyerarşisi teorisini desteklediği görülmüştür. Ayrıca alt sektörler bazında sermaye yapıları arasında farklılıklar olduğu tespit edilmiştir.

Çalışmanın ikinci bölümünde sermaye yapısına dair temel modeller anlatılmış, daha sonra sermaye yapısını belirleyen firmaya özgü faktörler hakkında yazında yapılmış çalışmalar özetlenmiştir. Üçüncü bölüm daha önce yapılan ampirik çalışma ve teorik yaklaşımlar çerçevesinde hipotezlerin oluşturulması, verilerin sunumu, uygulamanın icra edilmesi ve bulguların sunulması şeklinde oluşturulmuştur. Dördüncü bölümde ise çalışmanın sonuçları özet olarak aktarılmış ve çıkarımlarda bulunulmuştur.

\section{Literatür}

Modern sermaye yapısı teorisi ilk kez 1958 yılında Modigliani ve Miller tarafından geliştirildiğinden beri sermaye yapısı kararları ile firmanın değerinin değiştirip değiştirilemeyeceği araştırılmaktadır (Cortez \& Susanto, 2012: 121). Optimal sermaye yapısını belirlemek için çeşitli sermaye yapısı teorileri geliştirilmiş; ancak işletme ve finans yöneticilerinin optimal borç oranını belirlemek için kullanabilecekleri spesifik bir metot geliştirilememiştir (Sheikh \& Wang, 2011: 118). Fakat bu teoriler firmaların finanslama davranışlarını anlamaya ve sermaye yapısını etkileyen faktörlerin belirlenmesine yardımcı olmaktadir (Sheikh \& Wang, 2011: 118).

Modigliani ve Miller'in 1958'de yayınladıkları makale modern sermaye yapıs1 teorilerinin başlangıcı olarak kabul edilmektedir (Terim \& Kayalı, 2009: 126). Bu çalışmada piyasaların mükemmel işlediği ve vergi unsurunun göz ardı edildiği varsayımları altında, "ilişkisizlik teorisi/ilintisizlik teorisi (irrelevance principle)" adı verilen işletmenin değerinin sermaye yapısından bağımsız olduğu, borçlanarak işletme değerinin artırılamayacağı iddia edilmiştir (Cortez \& Susanto, 2012: 122). Daha sonra varsayımların gerçekçi olmayışına yönelik (işlem maliyetleri, iflas ve finansal sıkıntı maliyetleri, vergi faktörünün dikkate alınmaması, arbitraj olanaklarının kısıtlı olması gibi) (Akgünç, 2011: 501) akademik çevreden gelen eleştiriler üzerine yazarlar varsayımlarını güncellemiş ve ikinci teorilerini (1963) ortaya atmışlardır. Bu teoride borçlanmanın getirmiş olduğu vergi avantajı dikkate alınmış ancak finansal sıkıntı maliyetleri göz ardı edilmiştir. Bu şekilde, borçlanma yoluyla işletmenin piyasa değerinin yükseltilebileceğini iddia etmişlerdir (Başaran, 2008: 28). 
Daha sonraki sermaye yapısı teorileri, Modigliani ve Miller'in oluşturmuş olduğu teorik çerçeveye onların göz önüne almadıkları faktörler de dâhil ederek geliştirilmeye çalışılmıştır (Başaran, 2008: 28). Günümüzde sermaye yapısı teorileri, Krauz ve Litzebnerger (1977) tarafından geliştirilen statik bir yaklaşım olan dengeleme teorisi ve Myers ve Majluff (1984) tarafından geliştirilen finansman hiyerarşisi teorisi şeklinde iki yaklaşım üzerinde yoğunlaşmıştır (Cortez \& Susanto, 2012: 121). Bu teoriler de firmanın değerinin borçlanma ve sermaye yapısından bağımsız olduğunu reddetmektedir (Cortez \& Susanto, 2012: 123).

Dengeleme teorisi, borçla finansmanın getirdiği avantaj ve maliyetleri dikkate alarak firmaların optimal sermaye yapısını belirlediğini savunan sermaye yapısı yaklaşımıdır (Gülşen \& Ülkütaş, 2012: 50). Bu teoriye göre belirli bir noktaya kadar (optimal sermaye yapıs1) borçla finansmanın getirmiş olduğu vergi avantajı borcun getirmiş olduğu finansal sıkıntı maliyetlerinden yüksektir ve borçlanmak firma değerini artırmaktadır. Ancak optimal sermaye yapısı aşıldıktan sonra borcun maliyetleri vergi avantajını aşmakta ve firma değerini düşürmektedir (Yükeri, 2009: 39). Dolayısıyla söz konusu teori, firmanın optimal sermaye yapısını belirlemek için daima borcun marjinal faydası ve marjinal maliyetini hesapladığını savunmaktadır. Aynı zamanda dengeleme teorisi firmalara göre hedef borç oranlarının değişebileceğini iddia etmektedir. Teoriye göre, maddi duran varlık oranı yüksek ve borcun getirmiş olduğu vergi tasarrufundan faydalanmak için yeterli düzeyde vergilendirilebilir karı olan şirketlerin hedef borçlanma oranları daha yüksektir (Elitaş \& Doğan, 2013: 42).

Sermaye yapısı teorileri içinde dengeleme teorisinin en güçlü şekilde destek bulduğu dönemlerde bu modelin açıklayamadığı bazı firma davranışlarının olduğu anlaşılmıştır. Firmaların bir sermaye yapısı belirleyip ona doğru ilerlemeleri gerektiğini ortaya koyan dengeleme teorisine karşılık Myers ve Majluf (1984) asimetrik bilgi ve sinyal etkisi kavramlarından faydalanarak finansman hiyerarşisi teoremini sistematik olarak ortaya koymuştur. Bu teoriye göre şirketler finansman ihtiyacında öncelikli olarak iç kaynakları (dağıtılmamış karlar vb.) kullanmakta, bunun dışında ihtiyaç olması halinde dış kaynaklara yönelmektedir. Dış kaynakların sırası ise önce borç kullanımı daha sonra hisse senedi ihracıdır. Bu sıralamanın oluşmasında asimetrik bilgi ve sinyal etkisinin hisse senedi ihraç maliyetlerini yükseltmesi, yeni hissedarların şirket üzerindeki getireceği kontrol yetkisi, borçlanmanın getirmiş olduğu finansal maliyetler ve iç kaynakların gelir vergisi etkisinden dolayı maliyetinin küçülmesi gibi nedenler etkilidir (Myers \& Majluf, 1984). Bu sebeple finansman hiyerarşisi teoremine göre karlılığı yüksek olan firmalar daha az oranda karlılığ düşük olan firmalar daha yüksek oranda borçlanacaktır (Terim \& Kayalı, 2009: 128).

Sermaye yapısının belirleyicilerini açıklamaya çalışan başka teoriler olsa da karar verme sürecini etkileyen değişkenlerin oldukça fazla oluşundan, tek bir teori sermaye yapısı 
teorisinin tamamını açıklayamamaktadır (Cortez \& Susanto, 2012: 122). İşletmelerin sermaye yapısını etkileyen değişkenler, faaliyet gösterdikleri ülkenin genel ekonomik durumu, içinde bulundukları sektörün yapısı ve firmaya özgü değişkenler olmak üzere üç şekilde sınıflandırılabilir (Başaran, 2008: 8; Akgüç: 501-505). Nitekim Korajczyk ve Levy (2003) yalnızca işletmeye özgü faktörlerin sermaye yapısındaki değişimleri açıklayamadığını, faaliyet gösterilen endüstri ve içinde bulunulan ekonomik şartların da etkili olduğunu ifade etmiştir (Nelson \& Arshanapalli: 321).

Ülkenin mevcut ekonomik durumunu ve gelecekte nasıl seyredeceğine yönelik sinyaller işletmelerin sermaye yapısı kararları üzerinde etkili olmaktadır. Genel olarak ekonomide bir genişleme bekleniyorsa bu durum işletmelerin faaliyetlerine fayda sağlayacak ve fon bulmalarını kolaylaştıracaktır. Bu durumda işletmeler daha fazla borçlanabilecektir. Ekonomide bir daralma bekleniyorsa, işletmeler riskini yükseltmemek adına yabanıı kaynak kullanımlarını azaltacak ve daha çok öz sermaye ile finansmanı tercih edecektir (Başaran, 2008: 9). Özetle; GSYH veya GSYH'daki büyüme, enflasyon ve faiz oranları, sermaye ve para piyasalarının gelişmişliği, mevzuattaki vergi ve teşvik politikası, kambiyo pazarı ve döviz kurundaki gelişmeler, işletmelerin sermaye yapılarını etkileyen makroekonomik değişkenlerdir (Akgüç, 2011: 505-506).

İşletmeler sermaye yapısını oluştururken, ülkenin genel ekonomik durumunun yanında içinde bulunduğu endüstrinin koşullarından da etkilenmektedir (Yükeri, 2009: 17). İçinde bulunulan endüstrinin mevsimsel hareketlerden etkilenip etkilenmemesi önemli bir faktördür. Mevsimsel hareketlerden etkilenen işletmeler genellikle, geri ödeyememe risklerini azaltmak için, daha kısa vadeli esnek ödeme planlı borçlanma araçlarını kullanmakta ve daha çok öz sermaye ile finansmanı tercih etmektedir (Akgüç, 2011: 507). Sermaye yapısını etkileyen bir diğer önemli faktör faaliyet gösterilen endüstrinin konjonktür (dönemsel) hareketlerden etkilenip etkilenmemesidir. Çünkü gelir esnekliği yüksek, dayanıklı tüketim malları, sermaye malları gibi mallar üreten firmalar ulusal gelirdeki dalgalanmalardan büyük ölçüde etkilenmektedir. Böylesi endüstrilerde faaliyet gösteren firmalar için öz sermaye ağırlıklı finansman tercih edilebilmektedir. Rekabetin fazla olduğu endüstrilerdeki firmalar için de borç oranını düşük tutmak risk azaltıcı bir yöntem olarak kullanılmaktadır (Akgüç, 2011: 507-508). Ayrıca içinde bulunulan endüstrinin başlangıç, büyüme, olgunluk veya gerileme gibi hangi yaşam evresinde oluşu gibi faktörler de işletmelerin sermaye yapısını etkileyebilmektedir (Başaran, 2008: 11-12; Yükeri, 2009: 1819).

Sermaye yapısını etkileyen firmaya özgü değişkenler ise hipotezler kısmında teorik çerçevesiyle anlatıldığı için bu kısımda detaylı anlatılmamıştır. Ancak bu değişkenler: işletme şekli (hukuki yapı), varlık yapısı (maddi duran varlık oranı), işletme büyüklüğü (Zulfiqar vd, 2012: 1844), kredi değerliliği (Başaran, 2008: 13, 15, 95), firmanın büyüme 
arzusu, faaliyet kaldıracı (Başaran, 2008: 13, 15, 95), likidite (Zulfiqar vd, 2012: 1844), karlılık(Zulfiqar vd, 2012: 1844), borçlanma maliyeti, borç dışı vergi kalkanı (Başaran, 2008: 13, 15, 95) ve yöneticilerin tutumu şeklinde sıralanabilir (Akgüç, 2011: 509-511).

Aşağıda gerek yurtiçi gerek yurtdışında yapılan çalışmalar bulunan sonuçların hangi teorileri desteklediğine göre paragraflar halinde özetlenmiştir. Bu çalışmanın konusu imalat sanayi alt sektörleri olduğu için literatür taramasında bu sektörlere ağırlık verilmiştir.

Okuyan ve Taşçı (2010: 105), Türkiye'de sanayi şirketlerinin sermaye yapılarını 1993-2007 dönemi için 1000 şirket üzerinde incelemiş ve finansman hiyerarşisi kuramını destekleyen bulgulara ulaşmıştır. Acaravcı (2004: 134-136) imalat sanayi sektörünü; gıdaiçki-tütün, metal eşya-makine- gereç yapım, dokuma-giyim-deri, kimya-petrol-kauçukplastik, metal ana sanayi alt sektörleri bazında 1992-2002 dönemi için incelemiştir. Çalışmasında sermaye yapısını işletme dişı makroekonomik değişkenlerden çok firmaya özgü (işletme içi) değişkenlerin etkilediğini tespit etmiştir. İşletme içi değişkenlerin sermaye yapısına etkisi ise genel olarak finansman hiyerarşisi kuramını destekler niteliktedir. Dokuma- giyim-deri sektörü hariç sektörler arası bir farklılık bulunmamıştır. Ayrıca literatürden farklı olarak maddi duran varlık oranı ile sermaye yapısı arasında ilişki gözlenmemiştir. Yazar bu durumu maddi duran varlıklar yeniden değerleme hesaplarının öz kaynakları artırması dolayısıyla borç / öz kaynak oranını düşürmesi ile açıklamıştır. Yükeri (2009: 95) borsa dışından Adana Organize Sanayi Bölgesinde imalat sanayinde faaliyet gösteren 112 şirketin sermaye yapısını etkileyen faktörleri anket yöntemini kullanarak araştırmıştır. Araştırma sonunda işletmelerin genellikle hedef bir borç öz kaynak oranı belirlemediği bunun yerine maliyetlerine göre sırasıyla iç ve dış kaynakları kullandığını tespit etmiştir. $\mathrm{Bu}$ sonuç finansman hiyerarşisi kuramına göre hareket ettiklerini göstermektedir.

Ata ve Ağ (2010: 45-60) BİST’te işlem gören Metal Ana Sanayi ve Metal Eşya, Makine ve Gereç Yapım sektörlerinde işlem gören şirketler üzerinde firma karakteristiğinin sermaye yapısı üzerindeki etkisini araştırmıştır. Firma karakteristiğini temsil eden sermaye yapısının belirleyicileri olarak; likidite oranı, faiz karşılama oranı, firma büyüklüğü ve büyüme oranı bağımsız değişkenleri kullanılmıştır. Çalışma sonucunda, büyüklük ile sermaye yapısı arasında pozitif bir ilişkiye rastlanmıştır. Bu sonuç dengeleme teorisini destekler niteliktedir. Diğer tüm değişkenler ile (likidite oranı, faiz karşılama oranı, büyüme oranı) sermaye yapısı arasında negatif bir ilişkiye rastlanmıştır. Bu sonuçlar ise finansman hiyerarşisini destelemektedir. Terim ve kayalı (2009: 136-137) BİST'te işlem gören imalat sektöründeki firmaların sermaye yapılarını etkileyen faktörleri 2000-2007 yılları arasındaki verilerle araştırmış ve genellikle finansman hiyerarşisinin geçerli olduğunu tespit etmiştir. Maddi duran varlık oranı ile finansal kaldıraç oranı arasında bulunan ters yönlü ilişki dengeleme teorisinin geçerli olmadığını göstermektedir. Dengeleme teorisiyle uyumlu 
olarak firma büyüklüğü ile finansal kaldıraç oranı arasında aynı yönlü ilişki bulunmuştur. Karlılık değişkeni ile finansal kaldıraç oranı arasındaki ters yönlü ilişki de finansman hiyerarşisi teorisini desteklemektedir. Sarıŏlu ve diğ. (2013) 2007-2011 dönemleri için çimento ve otomotiv sektörlerinin sermaye yapılarının belirleyicilerini araştırmıştır. Bu çalışmada çimento sektöründe aktif büyüklük ile sermaye yapısı arasında aynı yönlü bir ilişki (dengeleme teorisini destekleyen), karlılık ile sermaye yapısı arasında ters yönlü (finansman hiyerarşisini destekleyen) bir ilişki bulmuştur. Sheikh ve Wang (2011) Pakistan KSE'de (Karachi Stock Exchange) işlem gören imalat sanayi sektöründe faaliyet gösteren 160 işletmenin sermaye yapısını etkileyen faktörleri, işletmelerin 2003-2007 arasındaki verileriyle incelemiştir. Kısa vadeli borçların bilanço içindeki büyüklügünden dolayı bağımlı değişken olarak toplam borçlar/toplam varlıklar oranını (borç rasyosu) kullanmıştır. Sonuçta karlılık ve likidite ile borç rasyosu arasında negatif yönlü bir ilişki bulmuştur. Bu bulgu finansman hiyerarşisi teorisini desteklemektedir. Firma büyüklüğü ve kazançların oynaklığı (volatilite) değişkenleri ile borç oranı arasında bulunan negatif yönlü bir ilişki dengeleme teorisini desteklerken; duran varlık/ toplam varlık oranı ile borç rasyosu arasındaki negatif ilişki dengeleme teorisinin ön görülerine aykırılık teşkil etmektedir. Borç dışı vergi kalkanı ve büyüme olanakları değişkenleri ile borç rasyosu arasında anlamlı bir ilişki bulunmamıştır. Cortez ve Sunato (2012) 3'ü otomotiv, 10’ü elektrikli aletler, 4'ü makina üretim, 3'ü eczacılık ve kimya, 1'i gıda olmak üzere imalat sanayi sektöründe faaliyet gösteren toplam 21 adet Japon işletmenin sermaye yapısının işletme özelinde belirleyicilerini araştırmıştır. Çalışma sonunda toplam borç/toplam öz sermaye bağımlı değişkeni ile büyüme arasında anlamlı bir ilişki bulunmamıştır. Bağımlı değişken ile maddi duran varlık/ toplam varlık değişkeni arasında pozitif, bağımlı değişken ile karlılık değişkeni arasında negatif yönlü bir ilişki tespit etmiştir. Bu sonuçların sırasıyla dengeleme teorisini ve finansman hiyerarşisi teorisini destekler nitelikte olduğunu ama her iki teorinin bir birine önemli bir üstünlük kuramadığını ifade etmiştir. Bu sebepten dolayı finansman hiyerarşisi teorisine göre ayarlanmış bir dengeleme teorisini, yani her iki teoriyi birleştiren yeni bir teorinin geliştirilmesini önermiştir.

\section{Veri Seti, Değişkenler, Metodoloji}

\subsection{Veri Seti}

Çalışmanın ana kütlesini imalat sanayi sektörüne ait BİST’te işlem gören şirketler oluşturmaktadır. İmalat sanayi sektöründeki şirketlerin alt sektörlere göre dağılımları Tablo 1' de gösterilmiştir. 
Tablo: 1

BİST’te İşlem Gören İmalat Sanayi Sektöründeki Şirketlerin Alt Sektörlere Göre Dağglımı

\begin{tabular}{|c|c|c|}
\hline Sıra & Alt Sektörler & Firma Sayıları \\
\hline 1 & Gıda, içki, tütün & 31 \\
\hline 2 & Dokuma, giyim eşyası ve deri & 27 \\
\hline 3 & Kağı ürünleri, basım ve yayın & 16 \\
\hline 4 & Kimya, petrol, kauçuk ve plastik ürünler & 33 \\
\hline 5 & Taş ve toprağa dayalı sanayi & 29 \\
\hline 6 & Metal ana sanayi & 17 \\
\hline 7 & Metal eşya, makine ve gereç yapım & 31 \\
\hline 8 & Orman ürünleri ve mobilya & 4 \\
\hline Toplam & & $\mathbf{1 8 8}$ \\
\hline
\end{tabular}

Kaynak: <http://www.kap.gov.tr/sirketler/islem-goren sirketler/endeksler.aspx>, 15.01.2015.

\subsection{Bağımlı Değiş̧kenler}

Sermaye yapısı ile ilgili yapılan çalışmalarda araştırmacılar bağımlı değişken olarak finansal kaldıraç oranlarını kullanmıştır. Bu çalışmada finansal kaldıraç oranı toplam borçların toplam pasiflere oranı şeklinde seçilmiştir. Söz konusu oran, çalışmanın devam eden kısmında "kaldıraç" olarak ifade edilmiştir.

\subsection{Bağımsız Değişkenler} sırlanmıştır.

Literatür çalışmalarından derlenen bağımsız değişkenler aşağıdaki gibi

\section{Değisken 1: Varlık Yapısı}

Maddi duran varlıkların yüksek olması şirketin tasfiye değerini artırmakta, iflas maliyetini düşürmektedir (Akman, 2012: 41). Bu durum alacaklıların firmaya daha kolay borç vermelerini sağlamaktadır. Ayrıca maddi duran varlıkları yüksek firmaların teminat gösterme olanağının fazla olması kolay kredi bulmalarını sağlayan bir başka etkendir (Demirhan, 2009: 681). Bu sebeplerden dolayı dengeleme teorisi varlıklar içinde maddi duran varlıkların payı ile borçlanma arasında pozitif yönlü bir ilişkinin varlığını ön görmektedir. Finansman hiyerarşisi teorisine göre ise söz konusu değişkenler arasında net bir ilişki öngörülememektedir (Cortez \& Susanto, 2012: 124; Sheikh \& Wang, 2014: 122). Wessels (1988), Rajan ve Zingales (1995), Fama ve French (2002) gibi birçok araştırmacı, sabit varlıkların toplam varlıklara oranı ile sermaye yapısı arasında dengeleme teorisini destekler nitelikte pozitif yönlü bir ilişki tespit etmiştir (Terim ve Kayalı, 2009: 128). Ancak 
literatürde maddi duran varlık oranı ile sermaye yapısı arasında negatif yönlü ilişkiler bulan veya herhangi bir ilişki bulamayan birçok çalışma da mevcuttur. Bunlara Acaravc1 (2004), Terim ve Kayalı (2009), Sheikh ve Wang (2011), Psillaki ve Daskalakis (2009)'in çalışmaları örnek olarak verilebilir.

\section{Değişken 2: Karlılık}

Bir firmanın optimal sermaye yapısının borçlanmanın getirdiği vergi avantajı ile finansal sıkıntı maliyetlerinin dengelenmesi sonucu oluştuğunu öneren dengeleme teorisine göre yüksek karlılığı olan firmaların borç kullanımı, firmanın karını kurumlar vergisine karş1 korumaktadır (Sheikh \& Wang, 2011: 121; Demirhan, 2009: 682). Aynı teoriye göre karlılı̆̆1 yüksek olan firmaların borç taşıma kapasitesi daha yüksek olacağından borçlanmanın getirmiş olduğu finansal sıkıntı maliyetleri daha düşük olacaktır. Bu sebeplerden dolayı, dengeleme teorisine göre karlılığı yüksek olan firmalar daha yüksek oranda borçlanabilecektir (Sarıoglu vd, 2013: 485). Oysaki finansman hiyerarşi teorisine göre işletmeler yatırımlarını ilk önce iç kaynaklarla (genellikle dönem karı veya dağıtılmayan karlar) gerçekleştirirler. Sonra sırasıyla dış finansman seçenekleri olan borçlanma ve hisse senedi ihraci gerçekleştirirler. Yani finansman hiyerarşisi teorisi karlılık arttıkça borçlanmanın azalacağını iddia etmektedir (Shah \& Kausar, 2012: 121). Karlı firmaların daha düşük iskontoyla hisse senedi ihraç edebilme şansı da borçlanmasını azaltıcı bir unsur olabilmektedir (Cortez \& Susanto, 2012: 125). Teorik yaklaşımlarda karlılık ve borçlanma arasındaki ilişki hakkında tam bir uzlaşıya varılamazken, ampirik çalışmalara bakıldığında da kimi çalışmalarda ilgili değişkenler arasında aynı yönlü kimi çalışmalarda tersi sonuçlara

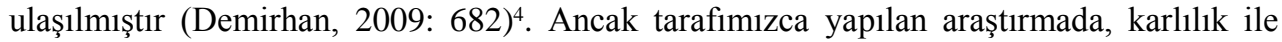
sermaye yapısı arasındaki ilişkinin genellikle negatif yönlü olarak bulunduğu gözlenmiştir.

\section{Değissken 3: Büyüklük}

Farklı büyüklükteki firmalar farklı karakterlere sahip olabilmektedir (Shah ve Kausar, 2012: 1844). Büyük firmaların iflas riskleri ve iflas maliyetleri daha düşük olacağ1 için borçlanmanın getirmiş olduğu finansal sıkıntı maliyetleri görece düşük olmaktadır. Aynı zamanda bu şirketler bilinirliklerinden dolayı daha düşük maliyetle borçlanabilmektedir. $\mathrm{Bu}$

4 Finansal kaldıraç ile karlılık arasında negatif ilişki bulan çalışmalara, Toy ve diğ. (1974), Titman ve Wessels (1988), Rajan ve Zingales (1995), Wald (1999), Booth ve diğ. (2001), Chen (2004), Bauer (2004), Tong ve Green (2005), Huang ve Song (2006), Zou ve Xiao (2006), Viviani (2008), Jong ve diğ. (2008), Serrasquerio ve Ragao (2009), Sheikh ve Wang (2011)'in çalışmalarl, Noulas ve Genimakis 'in (2011), Gülşen ve Ülkütaş (2012) 'ın çalışması örnek olarak verilebilir. Elitaş ve Doğan (2013)'un çalışması da tersi yönde sonuç veren (dengeleme teorisini destekleyen) çalışmalara örnek olarak verilebilir. 
sebeplerden dolayı dengeleme teorisi büyük firmaların daha fazla borçlanabileceğini iddia etmektedir (Frank \& Goyal, 2009: 7 \& Terim \& Kayal1, 2009: 129). Ancak büyük işletmeler için asimetrik bilgi sorununun azalması ile şirket hisse senedi ihraç etmeye de teşvik olabilmektedir. Bu sebeplerle finansman hiyerarşisi teorisi büyüklük ile borçlanma arasında negatif bir ilişki olduğunu öngörmektedir (Sheikh \& Wang, 2011: 122). Bu konuda teorik yaklaşımlarda olduğu gibi ampirik çalışmalar arasında da mutabakat sağlanamamıştır (Demirhan, 2009: 682). Wald (1999) büyüklük ile finansal kaldıraç oranı arasında; ABD, İngiltere ve Japonya firmaları için pozitif yönlü ve istatistiksel açıdan anlamlı; Almanya firmaları için negatif yönlü ve istatistiksel açıdan anlamsız ilişki tespit etmiştir (Sheikh \& Wang, 2011: 122). Marsh (1982), Bauer (2004), Deesomsak ve diğ. (2004), Zou ve Xiao (2006), Eritotis ve diğ. (2007), Sarrasqueiro ve Rogao (2009) finansal kaldıraç ile firma büyüklüğü arasında pozitif yönlü bir ilişki bulan diğer araştırmacılardır. Chen (2004) ise Çin firmaları için büyüklük ile uzun vadeli borç/ öz sermaye oranı arasında negatif yönlü ve anlamlı bir ilişki bulmuştur (Sheikh \& Wang, 2011: 122).

\section{Değissken 4: Likidite}

Dengeleme teorisi, yüksek likiditeye sahip işletmelerin sözleşmeden doğan faiz ve anapara gibi yükümlülüklerini yerine getirebilecek oluşlarından dolayı, finansal sıkıntı maliyetlerinde bir artış olmadan daha yüksek oranda borçlanabileceklerini ifade etmektedir (Sheikh \& Wang, 2011: 123). Finansman hiyerarşisi teorisine göre ise likiditesi yüksek firmalar yatırımlarını bu likidite ile yapabildikleri için daha az borçlanacaklardır (Sarıoğlu vd, 2013: 485). Deesomsak vd. (2004) ve Viviani (2008)'in çalışmaları finansman hiyerarşisi teorisini destekler nitelikte çalışmalardır. Bu çalışmada likidite oranı olarak çalışmalarda sıkça kullanılan asit test oranı kullanılmıştır. Ancak; literatürde likidite için cari oranı (dönen varlıklar/kısa vadeli yabancı kaynaklar) kullanan araştırmacılar da mevcuttur (Shah \& Kausar, 2012: 1844).

\section{Değişken 5: Büyüme}

Büyüme oranları ile sermaye yapısının ilişkisi kuramsal olarak net olmayıp, yapılan uygulamalı çalışmalarda da çelişkili sonuçlar ortaya çıkmıştır (Başaran, 2008: 96). Finansman hiyerarşisi teorisini savunan araştırmacılara göre hızlı büyüyen işletmeler yeni ve karlı yatırımları için daha fazla fona ihtiyaç duyacaklar ve bu durum işletmeleri birincil finansman aracı olan borçlanmaya yönlendirecektir. Dengeleme teorisine göre ise büyüyen firmaların hem temsil maliyetlerini artmakta hem de kreditörlerin risk algısındaki yükselişten dolayı borçlanma maliyetleri artmaktadır. Bu durum göreli hızlı büyüyen firmaların daha az borçlanmasını sağlamaktadır (Cortez \& Susanto, 2012: 126).

\section{Değisken 6: Faaliyet Kaldıract}


Faaliyet kaldıracı, satışlardaki değişmenin faiz ve vergi öncesi kardaki (FVÖK) yarattığı değişimi gösteren ölçüdür. Yüksek faaliyet kaldıracı satışlardaki küçük miktardaki değişimin FVÖK'te daha büyük değişim yarattığını gösterir (Başaran, 2008: 15). Faaliyet kaldıracı işletmenin sermaye yapısını etkileyebilmektedir. Faaliyet kaldıracı düşük olan firmalar finansal kaldıraca ağırlık verebilmekte yani borç/öz sermaye oranını artırabilmektedir. Faaliyet kaldıracı yüksek olan firmalar ise toplam riskini (bileşik riskini) artırmamak için borçla finansman oranını düşürebilmektedir (Benarje \& De, 2014: 40). Dolayısıyla dengeleme teorisi gereğince faaliyet kaldıracı yüksek olan işletmelerin finansal sıkıntı maliyetlerini azaltmak için borç kullanımını azalttığı kuramsal olarak savunulmaktadir.

\section{Değișken 7: Satışlardaki Dalgalanma}

Dayanıklı tüketim malları, sermaye malları veya diğer lüks mallar üreten firmaların satışları konjonktür hareketlerinden, ulusal gelirlerdeki dalgalanmalardan önemli ölçüde etkilenir. Ağır bir borç yükü, finansman riskini artırarak faaliyetlerin canlı olmadığı dönemlerde borç ödeme konusunda söz konusu firmaları güç durumda bırakabilir. Satışları yüksek dalgalanma gösteren dolayısıyla karları istikrarsız olan firmaların risklerini azaltabilmek için daha büyük oranda öz sermaye kullanmaları gerekmektedir. Böylece firmalar yüksek olan iş risklerini düşük finansman riski ile dengeleyebilmektedir (Akgüç, 2011: 507). Bu sebeplerden dolayı, dengeleme teorisi gereğince satışlarındaki dalgalanma yüksek olan işletmelerin finansal sıkıntı maliyetlerini azaltmak için borç kullanımını azaltığı savunulmaktadır (Moosa \& Li, 2012: 6; Psilakki \& Daskalakis, 2008: 326). Ancak satışlardaki dalgalanması yüksek olan firmaların nakit akışlarındaki dalgalanmanında yüksek olacağı gerekçesiyle, finansman hiyerarşisi teorisi böylesi firmaların daha yüksek oranda dış kaynaklara ihtiyaç duyacağını iddia etmektedir (Frank \& Goyal, 2009: 10).

\section{Değişken 8: Borç Dışı Vergi Kalkanı}

Borcun işletmelere vergi avantajı (vergi kalkanı) sağladığı bilinmektedir. Ancak vergilendirilebilir karı çok düşük veya negatif olan işletmeler bu avantajdan yeteri kadar yararlanamamakta ve faiz ödemelerinin yükünü daha fazla hissetmektedir. Amortisman giderleri de (borç dışı vergi kalkanı) işletmelere vergi avantajı sağlamakta ve borçla finansmandaki vergi kalkanının ikamesi olarak nitelendirilmektedir (Sheikh \& Wang, 2011: 122). Bu nedenle hem finansman hiyerarşisi hem dengeleme teorisi gereğince, diğer koşullar sabitken borç dışı vergi kalkanı yüksek olan firmaların borcun daha maliyetli hale gelmesinden dolayı daha az borçlanacağı kuramsal olarak kabul edilmektedir (Cortez \& Susanto, 2012: 125). Literatürde yapılan çalışmalarda sermaye yapısı ile borç dışı vergi kalkanı arasında genellikle negatif yönlü ilişkiler tespit etmiştir (Sarıoğlu vd. 2013: 485; Cortez \& Susanto, 2012: 125). Ancak aynı yönlü ilişki bulan çalışmalar da mevcuttur 
(Sheikh \& Wang, 2011: 122). Çalışmada kullanılan bağımlı ve bağımsız değişkenler ve bu değişkenleri temsil eden oranlar Tablo 2'de liste olarak gösterilmiştir.

Tablo: 2

Çalışmada Kullanılan Değişkenler

\begin{tabular}{|c|c|c|c|}
\hline Değişken & $\begin{array}{l}\text { Değişkenin } \\
\text { Türü }\end{array}$ & Kullanılan Değişken & Kullanıldığı Çalışmalar \\
\hline Kaldıraç (y) & Bağımlı & Toplam Borç / Toplam Pasif & $\begin{array}{l}\text { Sheikh, Wang (2011) } \\
\text { Başaran (2008) } \\
\text { Cortez, Susanto (2012) } \\
\text { Elitaş, Doğan (2013) } \\
\end{array}$ \\
\hline Varlık Yapısı $\left(x_{1}\right)$ & Bağımsız & $\begin{array}{l}\text { Maddi Duran Varlık / } \\
\text { Toplam Varlık (MDV/TV) }\end{array}$ & $\begin{array}{l}\text { Sheikh, Wang (2011), } \\
\text { Cortez, Susanto (2012) } \\
\text { Başaran (2008) } \\
\text { Elitaş, Doğan (2013) }\end{array}$ \\
\hline Karlılık $\left(\mathrm{x}_{2}\right)$ & Bağımsız & $\begin{array}{l}\text { Faiz ve Vergi Öncesi Kar / } \\
\text { Toplam Varlık (FVÖK/TV) }\end{array}$ & $\begin{array}{l}\text { Cortez, Susanto (2012) } \\
\text { Başaran (2008) } \\
\text { Sarığlu vd. (2013) } \\
\end{array}$ \\
\hline Büyüklük $\left(x_{3}\right)$ & Bağımsız & $\begin{array}{l}\text { Aktif Büyüklüğünün Doğal Logaritması } \\
\ln (\mathrm{TV})\end{array}$ & $\begin{array}{l}\text { Shah ve Kausar, 2012, } \\
1844 \\
\text { Elitaş, Doğan (2013) }\end{array}$ \\
\hline Likidite $\left(x_{4}\right)$ & Bağımsız & Asit Test Oran1 & Başaran (2008) \\
\hline Büyüme $\left(x_{5}\right)$ & Bağımsız & $\begin{array}{l}\text { Toplam Varlıklardaki Artış } \\
\left(\mathrm{TV}_{\mathrm{t}} / \mathrm{TV}_{\mathrm{t}-1}\right)-1\end{array}$ & $\begin{array}{l}\text { Cortez, Susanto (2012) } \\
\text { Başaran (2008) } \\
\text { Gülşen, Ülkütaş (2012) }\end{array}$ \\
\hline Faaliyet Kaldıracı $\left(x_{6}\right)$ & Bağımsız & $\begin{array}{l}\text { Brüt Kar (BK) / } \\
\text { Faiz ve Vergi Öncesi Kar (FVÖK) }\end{array}$ & Başaran (2008) \\
\hline $\begin{array}{l}\text { Satışlardaki } \\
\text { Dalgalanma }\left(x_{7}\right)\end{array}$ & Bağımsız & $\begin{array}{l}5 \text { yıl için; Satışların Toplam Varlıklara } \\
\text { Oranının Standart Sapması } \\
\text { Std. Sap. (SAT/TV) }\end{array}$ & Sheikh, Wang (2011) \\
\hline $\begin{array}{l}\text { Borç Dışı Vergi } \\
\text { Kalkanı }\left(x_{8}\right)\end{array}$ & Bağımsız & $\begin{array}{l}\text { Toplam Amortisman ve İtfa Payı / } \\
\text { Toplam Varlıklar TA/TV }\end{array}$ & Sarığlu vd. (2013) \\
\hline
\end{tabular}

\subsection{Metodoloji}

Bu çalışmada 8 farklı bağımsız değişken $\left(x_{1}, \ldots, x_{8}\right)$ ile sermaye yapısı bağımlı değişkeni (y) arasında doğrusal bir iliş̧kinin varlığını test eden aşağıdaki model kullanılmıştır:

$$
y_{f, t}=b_{0}+b_{1} X 1_{f, t}+b_{2} X 2_{f, t}+b_{3} X 3_{f, t}+b_{4} X 4_{f, t}+b_{5} X 5_{f, t}+b_{6} X 6_{f, t}+b_{7} X 7_{f, t}+b_{8} X 8_{f, t}+\varepsilon
$$

Y herbir firma (f) ve yıl (t) için sermaye yapısını; $\mathrm{x}_{1}$ : varlık yapısı, $\mathrm{x}_{2}$ : karlılık, $\mathrm{x}_{3}$ : büyüklük, $\mathrm{x}_{4}$ : likidite, $\mathrm{x}_{5}$ :büyüme, $\mathrm{x}_{6}$ :faaliyet kaldırac1, $\mathrm{x}_{7}$ : satışlardaki dalgalanma, $\mathrm{x}_{8}$ : borç 
dışı vergi kalkanını göstermektedir. Herbir değişkenin tanımı 3.2. bölümde yapılmıştır. Modelde ayrıcı herbir alt sektör için sektör kuklaları oluşturulmuş ve toplam 8 sektör kuklası modele eklenmiştir. Varlık yapısı ve büyüklük dışındaki değişkenlerin dağılımlarındaki çarpıklıklarından dolayı (skewed) bu değişkenler \%1 seviyesinde winsorize edilmiştir.

Modelin testi için rassal etkiler panel analizi kullanılmıştır. Rassal etkiler modeli, gözlemlenemeyen rassal firma etkilerinin kontrol edilmesini sağlamaktadır. Firmalar arasındaki farklılıkların, bağımlı değişkeni etkileyebileceği varsayıldığından bu model kullanılmıştır. İlk olarak, Breusch and Pagan (1980) Lagrange Multiplier (LM) testi yapılarak rassal etkilerin varlığı tespit edilmeye çalışılmıştır. Rassal firma etkilerinin varyansının sıfira eşit olduğunu öngören null hipotezi reddedilmiştir. Bu sonuca göre rassal etkiler modelinin OLS modeline tercih edileceği sonucuna varılmıştır. İkinci olarak, Hausman testi yapılarak rassal etkiler modelinin sabit etkiler modeline tercih edileceği sonucuna varılmıştır. Ayrıca Variance Inflation Factors (VIF) analizi yapılarak test sonuçlarında multicollinearitenin bir etkisinin olup olmadığı araştırılmış ve bu eğilim için bir kanıt bulunamamıştır. Son olarak regresyonda heteroskedasticity robust standard hatalar kullanılarak, zaman serisinde herhangi bir bağımlılık ihtimali kontrol edilmiştir.

Tablo: 3

\section{Tanımlayıcı İstatistikler}

\begin{tabular}{|l|c|c|c|c|c|c|}
\hline Değişkenler & $\mathbf{N}$ & Ortalama & SD & p25 & p50 & p75 \\
\hline Kaldıraç & 884 & 0,49 & 0,26 & 0,3 & 0,47 & 0,64 \\
\hline Karlılık & 884 & 0,06 & 0,10 & 0,00 & 0,05 & 0,10 \\
\hline Büyüklük & 884 & 19,03 & 1,66 & 17,89 & 19,04 & 20,03 \\
\hline Likidite & 884 & 1,60 & 2,08 & 0,71 & 1,04 & 1,63 \\
\hline Varlık Yapıs1 & 884 & 0,36 & 0,18 & 0,22 & 0,36 & 0,48 \\
\hline Faaliyet Kaldıracı & 704 & 4,57 & 8,50 & 1,53 & 2,29 & 3,99 \\
\hline Büyüme & 884 & 0,15 & 0,33 & $-0,01$ & 0,09 & 0,21 \\
\hline Borçdışı Vergi Kalkanı & 884 & 0,03 & 0,02 & 0,02 & 0,03 & 0,04 \\
\hline Satışlardaki Dalgalanma & 884 & 0,21 & 0,21 & 0,09 & 0,14 & 0,26 \\
\hline
\end{tabular}

$N$ : gözlem saylsı, Ortalama:aritmetik ortalama, SD:Standart sapma, p25:25.yüzdelik değer, p50:medyan, p75:75.yüzdelik değer

\section{Ampirik Sonuçlar}

\subsection{Tanımlayıcı İstatistikler}

Tablo 3, bu çalışmada kullanılan değişkenlerin tanımlayıcı istatistiklerini göstermektedir. $\mathrm{Bu}$ sonuçlara göre, imalat sanayi sektöründeki şirketler ortalama \%49 oranında kaldıraca sahiplerken, bu şirketler için karlılık oranı \%6'dır. Ortalama firma 
büyüklüğü 19.03, likitide 1.60, faaliyet kaldıracı ise 4.57dir. Maddi duran varlıkların toplam varlıklar içindeki oranı ortalama \%36'dır. Toplam varlıklardaki artış (büyüme) \%15 seviyesinde iken borç dışı vergi kalkanı ortalama \%3’tür. 2009-2013 yılları arasındaki satışlardaki dalgalanma oranı ise $\% 21$ 'dir.

Tablo 4, bu çalışmada kullanılan tüm değişkenler için pearson korelasyon katsayılarını göstermektedir. Değişkenler arasında korelasyon probleminin olmadığı görülmektedir. Tablo 6'ya göre, bağımlı değişken kaldıraç ile karlılık, büyüklük, likitide, varlık yapısı değişkenleri arasında negatif bir ilişki var iken, faaliyet kaldıracı, büyüme, borç dışı vergi kalkanı ve satışlardaki dalgalanma arasında pozitif bir ilişki vardır.

Tablo: 4

\section{Korelasyon Matrixi}

\begin{tabular}{|l|c|c|c|c|c|c|c|c|c|}
\hline & Kaldıraç & Karlılık & Büyüklük & Likitide & $\begin{array}{c}\text { Varlık } \\
\text { Yapıs1 }\end{array}$ & $\begin{array}{c}\text { Faaliyet } \\
\text { Kaldıracı }\end{array}$ & Büyüme & $\begin{array}{c}\text { Borçdışı } \\
\text { Vergi } \\
\text { Kalkanı }\end{array}$ & $\begin{array}{c}\text { Satışlardaki } \\
\text { Dalgalanma }\end{array}$ \\
\hline Kaldıraç & 1 & & & & & & & & \\
\hline Karlılı & $-0,1232$ & 1 & & & & & & & \\
\hline Büyüklük & $-0,0378$ & 0,1843 & 1 & & & & & & \\
\hline Likidite & $-0,4959$ & 0,1287 & $-0,0822$ & 1 & & & & & \\
\hline Varlık Yapı1s1 & $-0,0624$ & $-0,2788$ & $-0,0046$ & $-0,1745$ & 1 & & & & \\
\hline Faaliyet Kaldıc1 & 0,0882 & $-0,2337$ & $-0,0595$ & $-0,0848$ & $-0,0452$ & 1 & & & \\
\hline Büyüme & 0,0039 & 0,1105 & $-0,0581$ & 0,0948 & $-0,0787$ & $-0,0139$ & 1 & & \\
\hline Borçdış1 Vergi Kalkanı & 0,0282 & $-0,0978$ & 0,0535 & $-0,0809$ & 0,2064 & 0,0368 & $-0,152$ & 1 & \\
\hline Satışlardaki Dalgalanma & 0,2115 & 0,1233 & $-0,2887$ & $-0,0118$ & $-0,1714$ & 0,0165 & 0,2341 & $-0,1296$ & 1 \\
\hline
\end{tabular}

Tablo: 5

Sektörlere Göre Sermaye Yapısı

\begin{tabular}{|l|c|c|c|c|c|c|}
\hline Sektör & N & Ortalama & SD & p25 & p50 & p75 \\
\hline Gıda, İçki ve Tütün & 142 & 0,58 & 0,33 & 0,33 & 0,55 & 0,75 \\
\hline Dokuma, Giyim Eşyası ve Deri & 127 & 0,49 & 0,24 & 0,34 & 0,46 & 0,62 \\
\hline Kağı Ürünleri, Basım ve Yayın & 77 & 0,45 & 0,25 & 0,25 & 0,44 & 0,64 \\
\hline Kimya, Petrol, Kauçuk ve Plastik Ürünler & 148 & 0,49 & 0,24 & 0,33 & 0,46 & 0,61 \\
\hline Taş ve Toprağa Dayalı Sanayi & 143 & 0,32 & 0,20 & 0,18 & 0,27 & 0,38 \\
\hline Metal Ana Sanayi & 81 & 0,50 & 0,17 & 0,41 & 0,49 & 0,60 \\
\hline Metal Eşya, Makine ve Gereç Yapımı & 149 & 0,59 & 0,25 & 0,44 & 0,59 & 0,73 \\
\hline Orman Ürünleri ve Mobilya & 17 & 0,41 & 0,27 & 0,14 & 0,38 & 0,51 \\
\hline Ortalama & & $\mathbf{0 . 4 8}$ & & & & \\
\hline
\end{tabular}

Tablo 5'de imalat sanayi sektöründeki sekiz alt sektöre ait ortalama sermaye yapısı (Toplam borç/ Toplam pasif oranları) verilmiştir. Tablo 5 'den görüldüğü üzere en az borç oranına sahip olan sektörler, taş ve toprağa dayalı sanayi $(0,32)$ ve Orman ürünleri ve 
mobilya $(0,41)$ sektörleridir. En yüksek borç oranına sahip sektörler ise Gıda-içki ve tütün $(0,58)$ ve Metal eşya-makine ve gereç yapım $(0,59)$ sektörleridir.

\section{2. İmalat Sanayi Şirketlerinin Sermaye Yapılarının Belirleyicileri}

Aşağıdaki Tablo 6, imalat sanayi şirketlerinin sermaye yapılarının belirleyicilerini incelediğimiz rassal etkiler modelinin sonuçlarını sunmaktadır. $\mathrm{Bu}$ sonuçlara göre; karlılık, likitide, varlık yapısı ve satışlardaki dalgalanma ile kaldıraç arasında anlamlı ilişkiler vardır. Karlılık ve likidite değişkenleri ile sermaye yapısı arasında negatif yönlü ilişki bulunmuştur. Kaynak kullanım sırasını iç kaynaklar, borçlanma ve hisse senedi ihracı olarak sıralayan finansman hiyerarşisi teorisine göre karlılık ve borçlanma arasında negatif bir ilişki vardır (Shah \& Kausar, 2012, 121). Bu nedenle karlılık için bulduğumuz negatif katsayı finansman hiyerarşisi teorisini desteklemektedir. Diğer yandan yine finansman hiyerarşisi teorisine göre yüksek likitideye sahip olan firmalar bu likitide ile yatırımlarını gerçekleştireceklerinden daha az borçlanmak isteyeceklerdir (Sarığlu vd, 2013, 485). Negatif katsayıya sahip olan likitide bu nedenle finansman hiyerarşisi teorisini desteklemektedir.

Tablo: 6

Rassal Etkiler Modeli Regresyon Sonuçları

\begin{tabular}{|l|l|}
\hline & Kaldıraç \\
\hline Karlılık & $-0.273^{* * *}$ \\
\hline & {$[0.000]$} \\
\hline Büyüklük & -0.006 \\
\hline & {$[0.369]$} \\
\hline Likidite & $-0.057^{* * *}$ \\
\hline & {$[0.000]$} \\
\hline Varlık Yapısı & $-0.173^{* * *}$ \\
\hline & {$[0.000]$} \\
\hline Faaliyet Kaldırac1 & 0,0002 \\
\hline & {$[0.758]$} \\
\hline Büyüme & 0.015 \\
\hline & {$[0.511]$} \\
\hline Borç Dişı Vergi Kalkanı & 0.193 \\
\hline Satışlardaki Dalgalanma & {$[0.457]$} \\
\hline Constant & $0.166^{* * *}$ \\
\hline & {$[0.000]$} \\
\hline R-squared & $0.589^{* * *}$ \\
\hline $\mathrm{N}$ & {$[0.000]$} \\
\hline
\end{tabular}

N: gözlem sayısı, ***:\%1 derecesinde anlamlılık, parantez içindeki sayllar p değerlerini göstermektedir. 
İşletme riskinin önemli bir bileşeni olan satışlardaki dalgalanma ile sermaye yapısı arasında pozitif yönlü ilişki bulunmuştur. Bu sonuç da finansman hiyerarşisi teorisini desteklemektedir. Zira finansman hiyerarşisi teorisi nakit akışı daha oynak (volatil) olan firmaların daha yüksek oranda dış kaynaklara ihtiyaç duyacağını iddia etmektedir (Frank, Goyal, 2009: 10).

Varlık yapısı ve sermaye yapısı arasında negatif bir ilişki bulunmuştur. Buna göre varlıkları içerisinde maddi duran varlık oranı fazla olan firmalar daha az borçlanmaktadırlar. Ancak dengeleme teorisine göre borç verenler risk derecelendirmesini varlık yapısına göre yaparlar ve varlık yapısı ve kaldıraç arasında pozitif bir ilişki beklenmektedir. Ancak yapılan amprik çalışmalarda genellikle bu durumun tersi görülmektedir. Bunlara Acaravcı (2004), Terim ve Kayalı (2009), Sheikh ve Wang (2011), Psillaki ve Daskalakis (2009)'in çalışmaları örnek olarak verilebilir. Söz konusu negatif ilişkiyi Terim ve Kayalı (2009) temsil sorunu çerçevesinde açıklamıştır. Buna göre, teminat gösterilecek varlık oranının fazla olması, yöneticilerin optimalin üzerinde borçlanmasıyla sonuçlanabilir. Bu durumun iflas riskini arttırır ve borç verenler tarafından daha yakından takip edilen yöneticilerin borçlanma isteği azaltır. Bu nedenle varlık yapısı ve kaldıraç arasında negatif bir ilişki bulmak mümkündür. Acaravcı (2004) ise bu durumu maddi duran varlık oranı yüksek olan firmaların yeniden değerlemesinden kaynaklanan öz sermaye artışının Toplam borç/Öz sermaye ve Toplam borç/Toplam pasif oranını düşürmesine bağlamıştır.

Bağımsız değişkenler ile sermaye yapısı arasındaki beklenen ilişkiler ve tespit edilen iliş̧kiler Tablo 7'de özetlenmiştir.

Tablo: 7

Bağımsız Değişkenler ve Sermaye Yapısı Arasındaki İliş̧i

\begin{tabular}{|c|c|c|c|}
\hline $\begin{array}{c}\text { Bağımsız } \\
\text { Değişken }\end{array}$ & $\begin{array}{c}\text { Sermaye Yapısı ile Beklenen } \\
\text { Ilişki Yönü }\end{array}$ & Destekleyen Teori & $\begin{array}{c}\text { Sermaye Yapısı ile } \\
\text { Tespit edilen İliişki }\end{array}$ \\
\hline Karlılık & Negatif*/Pozitif** & $\begin{array}{c}\text { Finansman Hiyerarşisi*/ } \\
\text { Dengeleme Teorisi** }\end{array}$ & Negatif \\
\hline Büyüklük & Negatif*/Pozitif** & $\begin{array}{c}\text { Finansman Hiyerarşisi*/ } \\
\text { Dengeleme Teorisi** }\end{array}$ & - \\
\hline Likidite & Negatif*/Pozitif** & $\begin{array}{c}\text { Finansman Hiyerarşisi*/ } \\
\text { Dengeleme Teorisi** }\end{array}$ & Negatif \\
\hline Varlık Yapıs1 & Pozitif & Dengeleme Teorisi & Negatif \\
\hline Faaliyet Kaldıracı & Negatif & Dengeleme Teorisi & - \\
\hline Büyüme & Negatif*/Pozitif** & $\begin{array}{c}\text { Dengeleme Teorisi*/ } \\
\text { Finansman Hiyerarşisi** } \\
\text { Nengeleme Teorisi ve } \\
\text { Finansman Hiyerarşisi }\end{array}$ & - \\
\hline $\begin{array}{c}\text { Borç Dışı Vergi } \\
\text { Kalkanı }\end{array}$ & Negatif & $\begin{array}{c}\text { Dengeleme Teorisi*/ } \\
\text { Finansman Hiyerarşisi** }\end{array}$ & Pozitif \\
\hline $\begin{array}{c}\text { Satışlardaki } \\
\text { Dalgalanma }\end{array}$ & Negatif*/Pozitif** &
\end{tabular}




\section{Sonuç}

$\mathrm{Bu}$ çalışmada BİST’te işlem gören imalat sanayi sektörüne ait 188 işletmenin sermaye yapısı 2009-2013 dönem verileriyle incelenmiştir. Sermaye yapısının firmaya özgü belirleyicilerinin tespit edilmesi çalışmanın özünü oluşturmaktadır. Sermaye yapısı değişkenini temsilen (bağımlı değişken) toplam borç/ toplam pasif oranı kullanılmıştır. Açıklayıcı değişken olarak karlılık, büyüklük, likidite, varlık yapısı, faaliyet kaldıracı, büyüme, borç dışı vergi kalkanı ve satışlardaki dalgalanma değişkenleri kullanılmıştır. Bağımlı ve bağımsız değişkenler arasındaki ilişki rassal etkiler regresyon analizi ile tespit edilmiştir. Bağımlı değişkendeki değişimin \%36’lık kısmının firmaya özgü değişkenler ile açıklandığı görülmüştür. Bağımsız değişkenlerin her birinin bağımlı değişkenle olan ilişkisi incelendiğinde sonuçların genellikle finansman hiyararşisi teorisini desteklediği görülmüştür.

Karlılık ve likidite değişkenleri ile sermaye yapısı arasında bulunan negatif yönlü ilişki, hemen tüm amprik çalışmalardaki gibi finansman hiyerarşisini destekleyen bir sonuçtur. Satışlardaki dalgalanma ile sermaye yapısı arasındaki pozitif ilişki de finansman hiyerarşisi teorisni desteklemektedir. Varlık yapısı ve kaldıraç arasındaki negatif ilişki ise, aktifleri içerisinde maddi duran varlıkları fazla olan şirketlerin, dengeleme teorisinin aksine daha az borçlandığı göstermektedir. Bu sonuç amprik çalışmalarla örtüşmektedir.

Büyüklük ve büyüme değişkenleri ile sermaye yapısı arasında anlamlı bir ilişki bulunamamıştır. Bu sebeple 2015-2017 orta vadeli mali programda planlanan üretim ve büyümede imalat sanayi payının artırılmasına yönelik uygulamaların önümüzdeki yıllarda sektörün sermaye yapısının herhangi bir yönde etkileyeceği söylenememektedir.

Çalışma 2009- 2013 dönem güncel verileriyle yapılmıştır. Ancak sermaye yapısını belirleyen firmaya özgü faktörlerin sermaye yapısı ile arasındaki ilişkiler daha önceki yıllarda yapılan çalışmalardakine benzer sonuçlar üretmiştir. Bu noktada önemli bir değişiklik göze çarpmamıştır. Ancak imalat sanayi sektörün Toplam borç/ toplam pasif oranı 1993-2007 dönemi için \%60,7 (Okuyan \& Tasç1, 2010: 113) iken bu oranın 2009-2013 dönemi için önemli bir gerileme gösterdiği görülmüş ve \%48 olarak ölçülmüştür.

\section{Kaynakça}

Acaravcı, S.K. (2004), “Gelişmekte Olan Ülkelerde Sermaye Yapısını Etkileyen Faktörler: Türkiye’de Bir Uygulama”, Doktora Tezi, Çukurova Üniversitesi Sosyal Bilimler Enstitüsü.

Akgüç, Ö. (2011), Finansal Yönetim, Avcılol Basım, 9. Baskı, İstanbul. 
Akman, E. (2012), “Sermaye Yapısını Belirleyen İşletmeye Özgü Faktörler: İMKB'de İşlem Gören Sanayi Firmaları Üzerine Bir Panel Veri Uygulaması", Doktora Tezi, Bülent Ecevit Üniveristesi.

Ata, H.A. \& Y. A $\breve{g}(2010)$, "Firma Karakteristiğinin Sermaye Yapısı Üzerindeki Etkisini Analizi”, İstanbul Üniversitesi İktisat Fakültesi Ekonometri ve Ístatistik Dergisi, 11, 45-60.

Barlas, Y. \& N. Kaya (2013), "Parasal Genişleme Politikalarının Gelişmekte olan Ülke Portföy Akımları Kompozisyonuna Etkisi”, TCMB Ekonomi Notlarl, 1-10.

Başaran, Ü. (2008), “İMKB’ de İşlem Gören Otomotiv ve Otomotiv Yan Sanayi İşletmelerinin Sermaye Yapısı Kararlarını Etkileyen Faktörlerin Analizi”, Yüksek Lisans Tezi, Zonguldak Karaelmas Üniversitesi.

Benarje, A. \& A. De (2014), "Determinants of Corporate Financial Performance Relating to Capital Structure Decisions in Indian Iron and Steel Industry: An Empirical Study", Paradigm, 18(1), 35-50.

Cortez, M.A. \& S. Susanto (2012), "The Determinants of Corporate Capital Structure: Evidence from Japanese Manufacturing Companies”, Journal of International Business Research, 11(3), 121-134.

Deesomsak, R. \& K. Paudyal \& G. Pescetto (2004), "The Determinants of Capital Structure: Evidence from the Asia Pasific Region”, Durham Research Online, June, 387-405.

Demirhan, D. (2009) "Sermaye Yapısını Etkileyen Firmaya Özgü Faktörlerin Analizi: İMKB Hizmet Firmaları Üzerine Bir Uygulama”, Ege Akademik Bakış, 9(2), 677-697.

Elitaş, B.L. \& M. Doğan (2013), "Sermaye Yapısını Belirleyen Faktörler: İMKB Sigorta Şirketleri Üzerine Bir Araştırma", MÖDAV, 2013/2, 41-57.

Frank, M.Z. \& V.K. Goyal (2009), "Capital Structure Decisions: Which factors Are Reliably Important", Financial Management, 1-37.

Gülşen, A.Z. \& Ö. Ülkütaş (2012), "Sermaye Yapısının Belirlenmesinde Finansman Hiyerarşisi ve Ödünleşme Teorisi: İMKB Sanayi Endeksinde Yer Alan Firmalar Üzerine Bir Uygulama", ZKÜ Sosyal Bilimler Dergisi, 8(15), 49-59.

Moosa, I. \& L. Li (2012), "Firm-Specific Factors as Determinants of Capital Structure: Evidence from Indonesia", Review of Pacific Basin Financial Market Policies, 15(2), 1-17.

Myers, S.C. \& N.S. Mafluj (1984), “Corporate Finance and Investment Decision When Firms Have Information That Investors Don't Have”, Journal of Financial Economics, 13, 187-221.

Nelson, W. \& B. Arshanapalli (2014), "Using Quantile Regression to Examine the Capital Structure Decision of US Firms", International Journal of Business and Finance Research, 8(5), 18.

Noulas, A. \& G. Genimakis (2011), "The Determinants of Capital Structure Choice: Evidence from Greek Listed Companies", Applied Financial Economics, 21, 379-387.

Okuyan, H.A. \& H.M. Taşçı (2010), "Sermaye Yapısının Belirleyicileri, Türkiye'deki En Büyük 1000 Sanayi İşletmesinde Bir Uygulama”, BDDK Bankacılık ve Finansal Piyasalar, 4(1), 105-120.

Padron, Y. et. al. (2005), "Determinants Factors of Leverage: An Emprical Analysis of Spanish Corporations", Journal of Risk Finance, 6(1): 60-68. 
Psillaki, M. \& N. Daskalakis (2009), "Are the Determinants of Capital Structure Country or Firm Spesific”, Small Business Economics, 33(3), 319-333.

Sarığlu, S.E. \& E. Kurun \& H. Güzeldere (2013), “Sermaye Yapısının Belirleyicileri: İMKB'de İşlem Gören Çimento, Otomotiv ve Bilişim Sektörlerinin Sermaye Yapısı Analizi”, Ege Akademik Bakış, 13(4), 481-496.

Shah, S.Z.A. \& J. Kausar (2012), "Determinants of Capital Structure of Leasing Companies in Pakistan", Applied Financial Economics, 22, 1841-1853.

Sheikh, N.A. \& Z. Wang (2011), "Determinants Capital Structure, An Emprical Study of Firms in Manifacturing Industry of Pakistan”, Managerial Finance, 37(2), 117-133.

Terim, B. \& C.A. Kayalı (2009), "Sermaye Yapısını Belirleyici Etmenler, Türkiye'de İmalat Sanayi Örneği”, Sosyal Bilimler, 7(1), 125-154.

Titman, S. \& R. Wessels (1988), “The Determinants of Capital Structure Choice”, Journal of Finance, XLIII (1), 1-19.

Türkiye İstataistik Kurumu (2015), <http://www.tuik.gov.tr/PreHaberBultenleri.do?id=16076>, 15.12.2014.

Türkiye Odalar ve Borsalar Birliği (2008), Ekonomik Rapor.

Viviani, J. (2008), "Capital Structure Determinants: An Empirical Analysis of French Companies in The Wine Endustry", Internal Journal of Wine Business Research, 20(2), 171-194.

Yükeri, Y. (2009), “İmalat Sanayi İşletmelerinin Sermaye Yapısı Kararlarını Etkileyen Faktörlerin İncelenmesi: Adana Hacı Sabancı Organize Sanayi Bölgesi'nde Bir Uygulama”, Yüksek Lisans Tezi, Çukurova Üniversitesi Sosyal Bilimler Enstitüsü. 
Abdioğlu, N. \& D. Deniz (2015), "Borsa İstanbul'da İşlem Gören İmalat Sanayi Şirketlerinin Sermaye Yapılarının Firmaya Özgü Belirleyicileri”, Sosyoekonomi, Vol. 23(26), 195-213. 